\title{
SOBRE O MERGULHO NA DESCOBERTA DOS SONS - A EXPERIÊNCIA DE ESCRUTÍNIO DOS DADOS SONOROS ATRAVÉS DA SUA INSERÇÃO NO BANCO DE SONS DO BIEV ${ }^{1}$
}

\author{
Viviane Vedana
}

A proposta deste ensaio surge das reflexões que a análise de alguns cadastros de sons no Acervo Sonoro do Banco de Imagens e Efeitos Visuais ${ }^{2}$ (BIEV) suscitou. Antes de iniciar esta discussão sobre o acervo sonoro, é importante situar que o Banco de Imagens vem discutindo ao longo de seus dez anos de existência, questões relativas ao tratamento conceitual e metodológico das imagens produzidas nas diversas etnografias realizadas por seus pesquisadores, tendo em vista sua filiação aos estudos de memória coletiva e imaginário no contexto urbano contemporâneo ${ }^{3}$. Uma das preocupações centrais deste grupo de pesquisa, neste caso, é justamente o caráter documental destas imagens e a necessidade de reflexão sobre as formas de acervamento dos dados imagéticos produzidos em campo, como uma forma de se colocar como guardião da memória dos diversos grupos e comunidades estudadas na cidade de Porto Alegre. Trata-se de uma preocupação epistemológica que visa não só "guardar" as imagens produzidas em campo, mas gerar possibilidades de circulação destas imagens, de múltiplas combinações entre fotografias, vídeos, sons e textos, que narrem histórias do cotidiano urbano e que possam ser acessadas pelos mais diversos públicos.

O Acervo de Imagens Sonoras no Biev parte da construção de um processo de pesquisa e produção de conhecimento antropológico através das imagens sonoras captadas em etnografias realizadas na cidade, seu cotidiano, a ritimicidade das formas de vida de seus habitantes, os itinerários urbanos e formas de sociabilidade que

\footnotetext{
${ }^{1}$ Aproveitamos a ocasião para agradecer ao CNPq pela concessão de bolsa de doutorado que possibilita esta pesquisa.

${ }^{2}$ Estudo Antropológico de Itinerários Urbanos, Memória Coletiva e Formas de Sociabilidade no Mundo Urbano Contemporâneo, Projeto Integrado de pesquisa financiado pelo CNPq, coordenado pelas Professoras Cornelia Eckert e Ana Luiza Carvalho da Rocha, no âmbito do NUPECS, Núcleo de Pesquisa de Culturas Contemporâneas e do Laboratório de Antropologia Social, do PPGAS-UFRGS. A partir deste projeto, desenvolveu-se o BIEV, Banco de Imagens e Efeitos Visuais, que reúne coleções de imagens sobre a memória coletiva de Porto Alegre, e que pesquisa novas formas de disponibilização do patrimônio etnográfico da vida urbana. Ver www.biev.ufrgs.br .

${ }^{3}$ Para maiores esclarecimentos sobre a filiação teórica do Biev ver no site www.iluminuras.ufrgs.br a Revista Iluminuras, principalmente os artigos de Ana Luiza Carvalho da Rocha e Cornelia Eckert sobre Cidade, Memória e Imagem.
} 
compõem a vida urbana ${ }^{4}$. Este processo de pesquisa no qual o conhecimento do outro e de sua cultura se dá principalmente pelas formas de expressão sonora, temos batizado de etnografia sonora e, em artigo anterior (Rocha; Vedana; 2007) delineamos o campo de discussões antropológicas no qual se insere, bem como estabelecemos algumas distinções em relação à etnomusicologia, por exemplo. Assim, para o caso deste ensaio, trataremos com mais ênfase um possível desdobramento destas etnografias sonoras no interior do Biev que é justamente a organização do material de campo em coleções de imagens e seu acervamento em bases de dados que permitam a consulta e a recuperação destes dados sonoros de campo por diferentes sujeitos, através da pesquisa em seus campos de consulta.

\section{Acervo e Memória: fazendo repercutir as sonoridades da cidade}

Um dos objetivos da constituição deste acervo sonoro é a possibilidade de fornecer dados para pesquisas futuras, diferentes das pesquisas que geraram o dado, além da possibilidade de uso destes sons também para a construção de novas narrativas. No entanto, o que está aí colocado para além dos usos e possibilidades de pesquisas destas imagens sonoras, é justamente seu caráter de narrativa sobre o tempo da cidade. Ao pertencer ao acervo, misturado, combinado, com inúmeras outras imagens sonoras, um dado de campo acaba assumindo dimensões mais amplas do que a da pesquisa que o gerou, simplesmente por se tratar de uma pista sobre um tempo, um momento vivido por diferentes sujeitos (incluindo aí o sujeito do pesquisador) no cotidiano da cidade.

Os trajetos de pesquisa que geram dados sonoros, sobre os mais variados temas, constituem, dessa forma, um acervo sonoro sobre a cidade, pois acumulam sonoridades no tempo, sonoridades que acabam narrando a própria vida urbana, muitas vezes em seus pormenores. Estes dados sonoros contemplam "imagens de mundo" dos grupos e situações pesquisadas, dão pistas de um tipo de cidade, de determinados arranjos que se conformam aqui ou acolá, falam de uma comunidade de sentidos e de sentimentos (Maffesoli; 1987) que habitam determinados territórios da cidade. Acervar estas pistas, estes fragmentos do vivido que se expressam a partir do som, acaba se constituindo

\footnotetext{
${ }^{4}$ Em outro artigo desenvolvemos uma reflexão sobre a etnografia sonora como uma forma de produzir conhecimento em Antropologia, as perspectivas adotadas no Banco de Imagens e Efeitos Visuais para o estudo das imagens sonoras e sua inserção no campo de estudos da antropologia urbana, memória e imaginário. Rocha, Ana Luiza Carvalho da. Vedana, Viviane. "A representação imaginal, os dados sensíveis e os jogos da memória: os desafios do campo de uma etnografia sonora". In: Anais do VII Congresso de Antropologia do Mercosul (VII-RAM), Porto Alegre, 2007, CD-ROOM.
} 
como um compromisso de fazer durar ${ }^{5}$ estas imagens, na repercussão da matéria deste som, em termos de seu volume, intensidade, freqüência, duração, etc, características que carregam os simbolismos das formas que ordenam a vida humana em termos das formas sonoras. Neste caso, o acervo sonoro do Biev é composto de diversas imagens, que podem contradizer-se ou complementar-se, mas que falam da cidade e das etnografias no meio urbano realizadas por pesquisadores preocupados com as sonoridades.

É claro que as condições de acervo destas imagens sonoras no Biev estão relacionadas a procedimentos de pesquisa específicos, que se direcionam à construção de coleções de imagens, ou seja, à composição de conjuntos ordenados a partir de determinadas categorias (conceitos antropológicos) que estão enunciadas nestas imagens. É a partir desta construção de coleções de imagens para cada pesquisa realizada - que podem envolver imagens textuais, sonoras, fotográficas e videográficas que os dados sonoros são ordenados para serem inseridos no acervo. Na composição destas coleções pelos pesquisadores está colocada a discussão da disponibilização das imagens produzidas em campo não apenas na forma de documentários ou obras acabadas, que de forma geral abarcam uma pequena parte desta produção imagética da pesquisa de campo, mas também na forma de conjuntos de imagens ou fragmentos que deram origem aos documentários, ou também, que não participaram de sua montagem/edição.

Trata-se de um entendimento da imagem como patrimônio etnográfico que evoca múltiplos sentidos sobre sua origem cósmico-social e sobre o gesto que a produziu, portanto, estabelecendo um outro estatuto para as imagens, que não se pauta somente por elementos estéticos - no sentido da produção de uma imagem bem enquadrada, com bom estudo de luminosidade e ruídos para o caso do som, etc - mas principalmente por seu caráter documental sobre a cidade e a memória. Na produção de coleções etnográficas e posteriormente no acervo, é a negociação entre esta autoria do pesquisador que estabelece determinados pontos de vista sobre o fenômeno pesquisado

\footnotetext{
${ }^{5}$ No interior das pesquisas em etnografia sonora que temos produzido no Biev procuramos estabelecer os pontos aproximativos com as formas de etnografar a cidade que têm sido desenvolvidas pelos pesquisadores do grupo. Uma destas aproximações refere-se a uma etnografia da duração, proposta por Ana Luiza Carvalho da Rocha e Cornelia Eckert para a investigação da memória coletiva no meio urbano. Outra aproximação igualmente rica refere-se a etnografia de rua e o registro das imagens sonoras fugidias do cotidiano urbano. ECKERT, Cornelia \& ROCHA, Ana Luiza C. da "Imagens do tempo: por uma etnografia da duração" In: O tempo e a cidade. Coleção Academia II. Porto Alegre, Ed. da UFRGS, 2005,e o artigo "Etnografia de rua, estudos de antropologia urbana". In: RUA - Revista do Núcleo de Desenvolvimento da Criatividades da UNICAMP - NUDECRI. Campinas, SP, n. 9, março 2003.
} 
e registra estes pontos de vista, e a forma final a partir da qual a imagem se desvela como expressão cultural deste fenômeno que está em jogo, considerando ainda a reconfiguração (Ricouer; 1994) possível desta imagem ao ser lida por outro pesquisador.

Importante apontar aqui as distensões temporais presentes em todo este processo, desde a captação das imagens em campo, até a descoberta das coleções e finalmente em seu cadastro no acervo. Até este momento de acervamento (que certamente não é "último", já que esta imagem pode ser várias vezes escutada e também compor narrativas), a imagem sonora passou por re-significações que acabam lhe constituindo um determinado lugar no acervo. Um dos lugares a partir do qual esta imagem vai evocar a cidade e suas formas, e seu tempo.

\section{Acervo Sonoro do Banco de Imagens e Efeitos Visuais}

O acervo de sons do Biev é composto das imagens sonoras que são captadas em campo, nas etnografias realizadas por seus pesquisadores. Estas imagens sonoras podem ser de diversos tipos e apresentar diferentes formas: as sonoridades da ambiência de uma determinada rua, numa combinação de planos sonoros onde estejam presentes vozes, ruídos, gestos e também o contexto, ou o cenário que os enquadra, imagens sonoras mais especificas, concentradas nos detalhes de gestos e ações de determinadas pessoas, sem evocar diretamente o seu contexto, sonoridades da voz e suas formas de enunciação, enfim, estes são apenas alguns exemplos das sonoridades possíveis de serem construídas como imagens sonoras no meio urbano.

De forma breve, pode-se dizer que em campo, o etnógrafo que procede a captação de sonoridades, na construção compartilhada de imagens sonoras sobre o fenômeno pesquisado, obedece a determinados pontos de escuta pré-estabelecidos em seu roteiro de campo. Trata-se na verdade dos lugares a partir dos quais o pesquisador vai se posicionar para elaborar esta imagem, apontando o microfone para determinadas fontes e rejeitando outras. Diferente do enquadramento da câmera (de vídeo ou fotográfica), como seus limites bem estabelecidos sobre o que permanece dentro do quadro e o que fica hors champ, o enquadramento do som passa por outros constrangimentos, relacionados à sua forma de propagação, que impede o etnógrafo de determinar exatamente o que seria esse hors champ. Mesmo assim, ainda é possível 
fazer escolhas de como captar determinados sons, de como enfatizar outros, tendo em vista estes pontos de escuta.

A partir destes pontos de escuta, que podem se referir a ambiências, a microeventos e sociabilidades, a gestos e fazeres, a performance oral, narrativas e entrevistas, etc, cada um deles exigindo escolhas de captação diferenciadas em termos de aproximação/distanciamento, posicionamento do microfone e escolha de equipamento (a relação entre dispositivos cênicos e dispositivos técnicos), constitui-se um conjunto de imagens sonoras que vamos chamar aqui de brutas, pois fazem parte de um todo ainda "grudado" na cronologia das ações desenroladas em campo. De posse deste material sonoro, o pesquisador vai proceder à escuta destas imagens sonoras e a uma primeira classificação, ou seja, a uma delimitação de que sonoridades são estas que estão registradas, como elas podem ser separadas umas das outras, quais os diversos sentidos que estão ali colocados. Este momento de escuta das imagens produzidas em campo já se constitui como uma primeira configuração do vivido, pois a memória do etnógrafo da situação de campo confronta-se com o que efetivamente as imagens narram. Trata-se, portanto de um novo patamar de interpretação que vai permitir ao pesquisador desvendar as imagens sonoras e refletir sobre os seus sentidos.

É com estas questões em mente que deslocamo-nos para o segundo passo, efetivamente digitalizar e através de softwares adequados, decupar, "separar" as diversas imagens que compõem a totalidade da captação sonora realizada. Neste momento são estabelecidos limites que transformam este "todo" das imagens brutas em diferentes fragmentos, em diversas imagens sonoras que evocam os diferentes pontos de escuta adotados pelo pesquisador. Estas imagens poderão referir-se a ambiências ou detalhes, como já foi referido no inicio deste texto e podem ter diferentes durações, de alguns segundos a minutos, por exemplo. O que vai diferenciar estas imagens e possibilitar o "corte" que define o inicio e o fim de cada uma será uma combinação entre os pontos de escuta escolhidos e os sentidos evocados pelas imagens.

Temos chamado, no decorrer dos processos de pesquisa e tratamento das imagens sonoras, estes fragmentos que se desdobram da decupagem de um registro de $i$ son, termo cunhado por Michel Chion (2004) ao advogar o estatuto de imagem para o som, no caso das narrativas cinematográficas. Para este autor o som é tão importante quanto a imagem visual na composição da narrativa filmica. Para o caso do Biev, 
adotamos o termo $i$-son e falamos de imagem sonora, ao combinarmos as proposições de Chion sobre o som no cinema com os estudos sobre o Imaginário de Gilbert Durand (2001, 1988), atribuindo ao som o estatuto de imagem que evoca sentidos e simbolismos, que provoca elaborações por parte de uma consciência imaginante (BACHELARD; 1996; 2000) que pensa o mundo e a si no tempo.

Assim, tendo estes $i$-sons decorrentes da decupagem, resta acervá-los na base de dados. Foi com este objetivo que criamos uma espécie de banco de dados, com um formulário de cadastro e de pesquisa onde estão dispostas diversas informações sobre os $i$-sons produzidos em nossas pesquisas, sendo uma delas a localização deste som fisicamente, ou seja, disponível para diferentes usos de pesquisa.

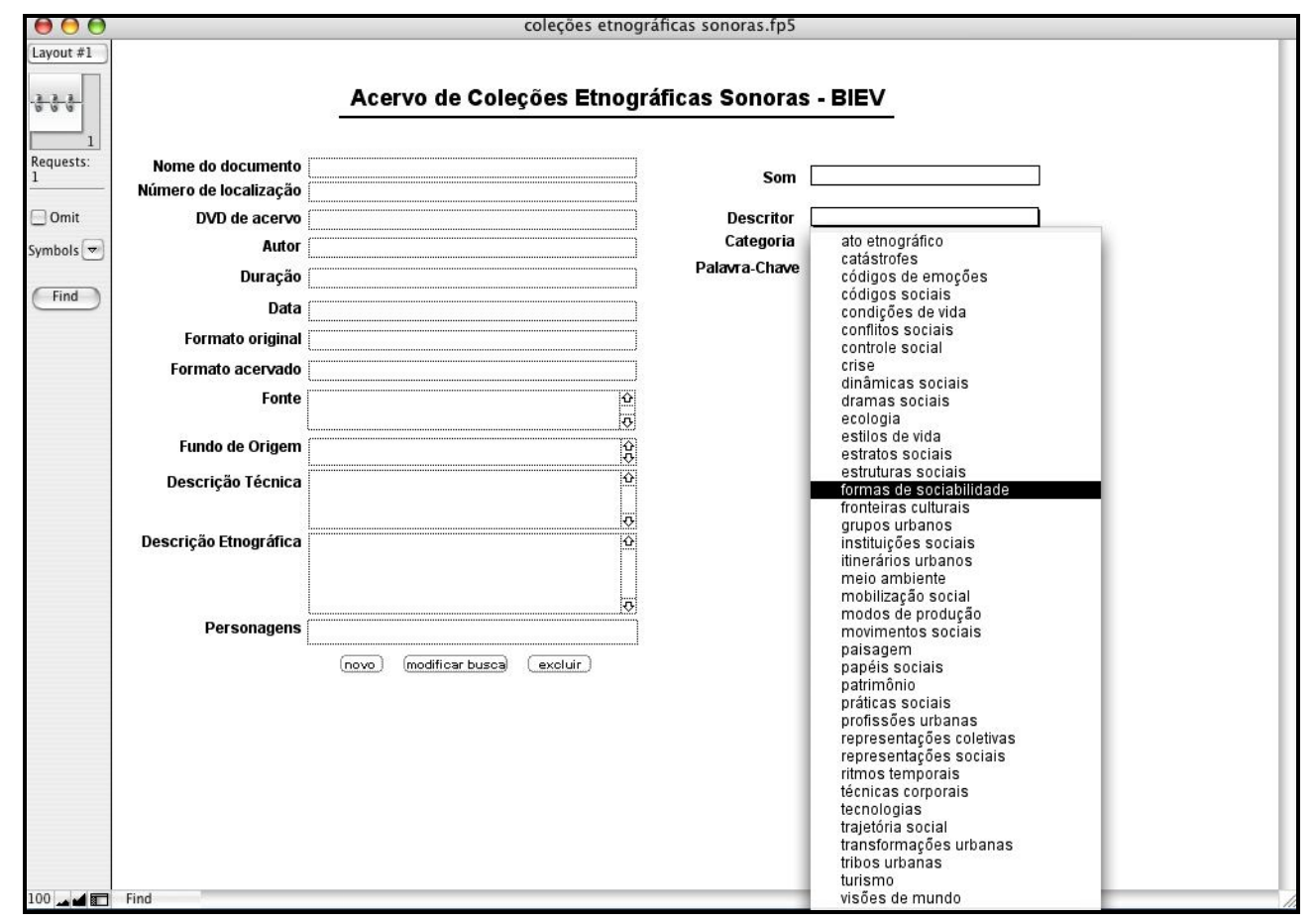

Todos os sons que são produzidos nas pesquisas etnográficas realizadas por pesquisadores do Biev estão/estarão disponibilizados neste acervo, em DVD, e podem ser consultados através das informações deste formulário. Além das informações, uma amostra deste som é disponibilizada diretamente no formulário, em formato $\mathrm{mp} 3$, para que o usuário possa escutá-lo no momento da pesquisa.

A titulo de "visualização" deste formulário, cabe colocar que os campos a serem preenchidos pelo pesquisador ao acervar seus dados sonoros são: 
01. nome do documento

02. numero de localização

03. dvd de acervo

04. duração

05. Data do documento

06. formato original

07. formato acervado

08. Fonte
09. Fundo de origem

10. descrição técnica

11. descrição etnográfica

12. personagens

13. som

14. descritor

15. categorias

16. palavras-chaves

O que gostaríamos de discutir neste texto é a relação entre estes campos e sua forma de preenchimento, tendo em vista os movimentos interpretativos realizados pelo pesquisador ao analisar a imagem sonora tendo como referência cada uma das informações demandadas pelo campo a ser preenchido. Além disso, destacaremos a importância e o significado do campo descritor, ao falarmos de imagem sonora, ou seja, suas potencialidades de descrever, pela forma, a imagem sonora a qual corresponde. Para isso, faremos inicialmente uma breve definição de cada um dos campos, em termos de que tipos de informação demandam para o preenchimento e depois elegeremos algumas relações entre eles, que são fundamentais no processo de pesquisa e análise destas imagens.

O objetivo deste texto é refletir sobre a construção deste acervo como um trabalho de pesquisa destas imagens, já que a partir dele elas são classificadas e também densamente observadas, escrutinadas, para que se finalize o preenchimento dos campos. Este texto busca apresentar a condição necessária de deslocamento epistemológico para o cadastro destes sons ao preenchermos os diferentes campos já que, a cada informação que o pesquisador vai inserir nestes campos, um aspecto deste $i$-som está sendo analisado. Nestes procedimentos, onde o pesquisador desloca-se entre os campos de informação, há o deslocamento também entre essas facetas do documento sonoro, que podem ser complementares, mas também opostas, em certos sentidos. Passar de um campo a outro no momento do preenchimento do formulário é deparar-se com os constrangimentos da matéria que estamos analisando, seus dados mais técnicos, as informações mais imediatas, em contraste com a interpretação de sentidos, com a idéia de uma forma sonora, com a dimensão de encontro etnográfico. 


\section{Os campos e a escrita da imagem sonora}

Um grande desafio da produção deste acervo sonoro é a transcrição ou tradução da imagem sonora para o registro escrito. Este esforço de "escrever o som" é que nos permite um certo distanciamento interpretativa da imagem, ao mesmo tempo que provoca a adesão a mesma, conforme os tipos de campos do formulário de cadastro que estamos preenchendo. É neste sentido que transcrevemos abaixo as características de cada campo.

1. nome do documento: pode ser um campo considerado de "informação imediata" já que, provavelmente, ao cadastrar um som ao acervo, o pesquisador já terá passado pela árdua tarefa de batizá-lo, ao realizar a decupagem, então, no preenchimento do formulário, resta reproduzi-lo;

2. número de localização: no caso do formulário criado para o acervo de sons, este número é gerado automaticamente pelo software, e existe por um motivo de ordenação e localização dos arquivos em seu suporte físico. Para facilitar a pesquisa dos interessados neste acervo, optamos pela numeração, além do nome do documento. Faz parte da identidade deste som, digamos assim, já que garante sua rápida localização;

3. dvd de acervo: também um dado imediato, pois refere-se ao suporte físico do som, indica em que DVD podemos encontrá-lo;

4. duração: esta é outra informação imediata, já que o som a ser acervado já passou pelo processo de decupagem, já tem definido quantos minutos ou segundos de duração ele tem, faz parte das propriedades do próprio arquivo;

5. data do documento: trata-se de uma reflexão de quando este dado foi gerado pelo pesquisador. Aqui temos um procedimento um pouco mais elaborado, já que temos duas datas possíveis: o momento da captação, ou o momento da decupagem. O que é importante nesta informação é a referência temporal a uma determinada época, momento histórico-social no qual foi realizada a pesquisa. Não importa tanto a data exata em que este documento existiu como tal, com dia/mês/ano, mas uma aproximação a partir do desenvolvimento da pesquisa, o ano, principalmente. Ao trabalharmos com a perspectiva da memória coletiva 
no meio urbano, este dado sonoro cadastrado no acervo constitui-se como um fragmento de um dado momento, de uma certa temporalidade da cidade;

6. formato original: novamente uma "questão técnica", ou seja, esta imagem sonora foi gerada de que maneira (wave, mp3, aiff, etc). É um dado imediato se o pesquisador, ao trabalhar este som, não fez nenhuma conversão no arquivo até o momento do acervo, ou seja, ele continua no mesmo formato em que foi gerado, neste caso, esta informação faz parte das propriedades do arquivo. Se houveram conversões, então será necessário que o pesquisador possa recuperar esta informação;

7. formato acervado: o formato de acervo será sempre prioritariamente WAVE, devido a manutenção da qualidade da imagem sonora. No entanto, arquivos gerados, no momento da gravação, em outros formatos, poderão ser acervados com o formato original se a conversão para wave for prejudicial à qualidade do mesmo. Do mesmo modo, arquivos que foram gerados em wave, mas convertidos para outros formatos precisam "voltar" ao formato wave para o acervo, desde que não seja prejudicada a imagem sonora neste procedimento de conversão;

8. fonte: esta informação coloca o pesquisador diante das diversidade de seus dados de pesquisa, ao refletir sobre de onde vem estes dados. Pode ser, no caso do som, de sua própria captação, do trabalho de campo, mas pode ser também de um outro acervo sonoro, de discos, cd's ou fitas K7. A primeira vista pode considerar-se uma "informação imediata", mas considerando a complexidade das pesquisas etnográficas, trata-se de uma reflexão importante em termos do uso e produção de imagem no âmbito da antropologia;

9. fundo de origem: neste caso pode se referir a própria pesquisa desenvolvida por quem está cadastrando o dado sonoro, ou pertencente a outros acervos, como a própria base de dados do Biev. Ao preencher este campo, estamos diante da reflexão da pesquisa que realizamos inserida em um contexto mais amplo, pois é possível confrontá-la, com as outras pesquisas que estão colocadas no acervo sonoro do BIEV;

10. descrição técnica: até aqui não falamos em escutar o som para preencher o formulário, mas é neste momento que esta necessidade aparece. Aqui 
precisamos descrever, com certa precisão, o que acontece nesta imagem, desde “defeitos" como batidas no microfone, ruídos não identificáveis, até condições do ambiente, como vento, sobreposição de vozes e sons, o que está audível ou não, o que está bom e claro, etc. Vejamos que para fazermos esta descrição há um giro epistemológico "obvio", que é parar para escutar o som;

11. descrição etnográfica: mais um deslocamento, pois saímos da dimensão da técnica da imagem, para descrever a situação etnográfica propriamente dita. São ambiências, de que lugar? São falas de informantes? Caracterizam-se por entrevistas ou conversas informais? Como foi feita a gravação? Neste campo nos deparamos com informações que não estão necessariamente colocadas no som, pois falamos aí do ponto de vista de quem "estava lá”, é diferente, portanto, do campo acima, que trata do som e suas características "técnicas";

12. personagens: nome dos informantes, se aparecem no som. A referencia a "quem é” esta pessoa, aparece na descrição etnográfica, campo acima. Este é quase uma "continuidade" do campo descrição etnográfica;

13. som: é o campo para inserirmos a imagem sonora, para que possa ser ouvida ao consultar o cadastro. Em termos dos procedimentos de cadastro, imagino que está seria a primeira ação;

14. descritor: trata-se de um de nossos mais importantes problemas de pesquisa no Biev, o da descrição das imagens sonoras. É também o deslocamento epistemológico mais "violento", pois para proceder a esta descrição, precisamos nos descarnar de todas as outras informações preenchidas, para atentar única e exclusivamente a imagem, à forma da imagem e não a seu conteúdo. O descritor vai descrever a forma sonora, e neste momento, estamos completamente a mercê deste som, ele é quem diz o que estará nesta descrição. Será que conseguimos abdicar desta autoridade sobre a imagem? Importante constar, para este campo descritor, a necessidade de uma análise bem refinada, de várias escutas, para identificarmos que sons são estes e como descrevê-los em palavras;

15. categorias: trata-se de uma classificação conceitual do som, a partir de forma e conteúdo. A categoria vai ser atribuída principalmente tendo em vista o campo de conceitos em que está colocada a pesquisa etnográfica. No caso do acervo de sons, as categorias são as mesmas definidas para o Banco de Imagens. Uma das 
pistas para atribuir uma categoria é a própria localização deste dado sonoro nas coleções etnográficas de cada pesquisador;

16. palavras-chave: também atribuídas a partir das palavras-chaves do Biev, representam uma forma mais operacional de interpretação e uso das imagens, em relação as categorias. As palavras-chave podem, neste caso, produzir o efeito de abertura de sentido para a interpretação desta imagem que, mesmo estando relacionada a uma grande categoria de interpretação, pode expressar-se em diferentes feições desta classificação.

\section{As relações entre os campos}

Como vimos a partir desta breve descrição de cada campo, estes podem ser divididos em alguns blocos. Em primeiro lugar o que chamamos aqui de "informação imediata", o que isso quer dizer? Referimo-nos ás informações que podemos acessar com um simples gesto, ao posicionar o cursor do mouse sobre o arquivo digital registrado no computador. Ao fazer este gesto, acionamos informações como a duração do arquivo, o formato em que se encontra e seu título.

Os dados de número de localização, que é preenchido pelo próprio programa, e DVD de acervo são importantes em termos do volume de documentos já acervados no banco de sons e podem também ser objetos de importantes reflexões, em termos dos procedimentos de trabalho coletivo, já que há uma rotatividade (no tempo da semana, por exemplo) de quem se dirige ao formulário para realizar o acervo. Estes campos apelam para um nível de reflexão que chamaremos aqui de "secundário" em relação a outros campos, pois não exigem necessariamente do pesquisador a mesma atenção e capacidade descritiva sobre a imagem sonora. Aqui também poderíamos colocar o campo som, tendo em vista que seu preenchimento constitui-se de um gesto incorporado de inserir um arquivo de som para o interior do formulário, produzindo um efeito de naturalidade diante da tecnologia utilizada. $\mathrm{O}$ gesto de inserir o som, neste caso, não é explicitamente objeto de reflexão.

Em relação a outras informações do formulário a ser preenchido, temos um acesso um pouco diferenciado, que nos demandam um momento de reflexão sobre a própria pesquisa realizada: Data, fonte, fundo de origem, formato original são campos que nos remetem ao contexto da pesquisa e ao processo de sua produção, bem 
com a memória da mesma. Como comentado acima, trata-se de perceber a imagem sonora que está sendo acervada como parte de um todo, onde estão combinadas a outras imagens, a dados estatísticos, enfim, ao conjunto de dados sensíveis que compõem uma pesquisa etnográfica. Refletir sobre estes campos de informações no acervo de sons do Biev significa deparar-se com a memória da própria pesquisa até aquele momento, no sentido das continuidades e descontinuidades (Bachelard; 1988) que marcaram a produção dos dados de campo, a interpretação destes dados, e a produção de escritas etnográficas, em sentido amplo. Podemos dizer que se trata do caráter documental do próprio banco de sons, pois ali se inscreve o registro da temporalidade desta imagem, em termos de sua produção empírica, ao mesmo tempo em que confronta as diversas imagens acervadas entre si, no que concerne as múltiplas temporalidades de produção sonora realizada pelos pesquisadores do Biev. Estes campos, então, guardam ainda a dimensão etnográfica do próprio preenchimento do formulário, tendo em vista a duração desta imagem como dado de pesquisa no tempo, para além do pesquisador que o produziu. Ao mesmo tempo em que provoca uma reflexão sobre a pesquisa que está sendo realizada, tensiona esta mesma pesquisa com as outras pesquisas presentes ao acervo, configurando assim um quadro complexo das pesquisas no interior do Biev, enquanto produtor de conhecimento antropológico a partir de imagens.

Um outro bloco de "informações" seria formado pelos campos descrições técnica, descrição etnográfica, descritor, palavras-chave e categorias. Note-se que a adesão às imagens sonoras a partir do processo de acervamento vai se densificando. Este bloco constitui-se como um mergulho interpretativo na imagem sonora. Mesmo o campo descrição técnica, que a primeira vista parece indicar informações "práticas" sobre o som, constitui-se como um campo que depende da escuta e de certo nível de interpretação desta escuta. Isso porque não estamos preocupados - não essencialmente com timbres, altitudes, frequiências, grãos, mas com informações que fazem parte das condições de gravação, da "audibilidade" de vozes ou sonoridades específicas presentes a imagem.

Aqui também temos a dimensão de uma reflexão etnográfica, pois descrever um som tecnicamente vai conduzir a uma melhor forma de registro destas imagens em campo, já que confronta o pesquisador com as limitações de suas escolhas de dispositivos técnicos e cênicos de gravação. Vejam que é diferente de apenas escutar as 
imagens no pós-campo e perceber suas limitações, no caso do acervamento destas imagens, esta informação passa pelo registro escrito sendo, portanto elaborada conceitual e metodologicamente pelo pesquisador. Com isso, este procedimento de acervo sistemático possibilita a construção de conhecimento sobre a etnografia sonora que nos permite ensiná-la a outros pesquisadores interessados em pesquisar as sonoridades da vida urbana.

A descrição etnográfica, a principio, é o campo que mais dominamos, já que se refere ao estar lá (Geertz; 2002), ao momento de produção do dado sensível. Mais um momento do acervo e cadastro das imagens sonoras que nos conduz a memória do processo de pesquisa, pois precisamos voltar - a partir de hoje, e do som que resultou do trabalho de campo - ao momento da situação etnográfica, ouvindo o som e descrevendo lugares, pessoas, relações e papéis sociais, etc. Neste campo, tudo o que está presente no som precisa ser descrito: as sonoridades de objetos e utensílios, as vozes e falas, os burburinhos e texturas que podem não ser imediatamente identificáveis. Mais uma vez, trata-se de um exercício de escrita, de descrição, das sonoridades que compõem o campo de cada pesquisador. Em se tratando de um fragmento de uma imagem não figurativa, estas informações são importantes para o próprio registro temporal da situação etnografada sonoramente. Este campo guarda uma relação de complementaridade com o campo descrição técnica, no que tange a interpretação da imagem sonora.

Os campos categoria e palavras-chaves são fechados, ou seja, o pesquisador deve escolher entre as que estão disponíveis no próprio campo. As categorias e as palavras-chave disponíveis para o cadastro no acervo de sons são as mesmas que compõem a base de dados do Banco de Imagens e Efeitos Visuais. Trata-se de conceitos da Antropologia e das Ciências Sociais a partir dos quais as imagens podem ser classificadas dentro de um campo de pertença, por exemplo, a imagem sonora pode estar evocando formas de sociabilidade, práticas cotidianas, estilos de vida, etc. Ao cadastrar no acervo de sons, o pesquisador deve escolher apenas uma categoria, referente a um conceito mais abrangente, e quatro palavras-chave, referentes às diferentes feições do fenômeno representado na imagem. A escolha das categorias e palavras-chave constitui-se como um momento de conceituação da imagem por parte do pesquisador. No caso dos pesquisadores do Biev, este procedimento está relacionado à 
construção das coleções etnográficas da pesquisa desenvolvida por eles, que exige da mesma forma, a reunião dos dados sensíveis produzidos em campo a partir de determinados conceitos que permeiam a pesquisa ${ }^{6}$.

O campo descritor é um dos mais complexos a ser preenchido, pois se trata de um movimento interpretativo que demanda distanciamento do dado empírico e etnográfico que está contido no som, para uma dedicação quase exclusiva a descrição imagética, ou seja, da forma e não do conteúdo do som. No caso do acervo de sons do Biev, não optamos em um primeiro momento por descritores pré-estabelecidos, mas pela construção de descritores conforme as imagens sonoras a serem cadastradas. Neste caso, os pesquisadores que procedem ao acervo têm a possibilidade de criar novos descritores ou utilizar descritores que já foram criados por outros. Trata-se, no entanto, de um processo que exige bastante atenção, referindo-se sempre a uma combinação entre as categorias antropológicas de classificação deste som e sua forma.

Neste caso, podemos refletir sobre a questão dos descritores através de algumas perguntas: Que termos ou que palavras teriam a potência de descrever uma imagem sonora? Como representar por estas palavras as diferenças entre as imagens sonoras que se referem a gestos, a ambiências e a falas? Todas as vozes são iguais? Como nomear as diferenças de gênero, idade, estilo de vida, na forma de falar, na voz?

Não pretendemos ter respostas imediatas para estas perguntas, mas gostaríamos de fazer aproximações em termos do tipo de perspectiva epistemológica que precisamos adotar para nos dedicarmos ao preenchimento deste campo Descritor. A idéia do campo descritor não ser "fechado" como no caso das categorias e palavras-chave, tem relação principalmente com a necessidade de se refletir sobre as especificidades das imagens sonoras presentes ao acervo e as formas como expressam a cultura e os fenômenos sociais que as configuram. É claro que com o crescimento do acervo, portanto com o aumento do número de descritores, torna-se possível um processo mais amplo de generalização - de determinados descritores a vários sons - pois além de nos

\footnotetext{
6 Ver a respeito o texto Vedana, Viviane." Sonoridades da Duração: práticas cotidianas de mercado no mundo urbano contemporâneo. Uma introdução à construção de coleções etnográficas a partir dos dados imagéticos de campo." In: Anais do VII Congresso de Antropologia do Mercosul (VII-RAM), Porto Alegre, 2007, CD-ROOM, podem ser encontradas também algumas referencias sobre a construção de coleções etnográficas na pesquisa antropológica com imagens.
} 
apropriarmos deste lugar de descrição formal ${ }^{7}$ (Maffesoli; 1988) da imagem sonora, construímos aproximações entre as sonoridades produzidas por pesquisas diferentes.

Tendo como referência alguns dos primeiros descritores elaborados pelos pesquisadores ao acervarem suas imagens sonoras, levantaremos algumas questões para reflexão. Uma das primeiras hipóteses destes pesquisadores foi utilizar como descritores os termos testemunho, conversa informal ou entrevista, por exemplo, termos que se referem a técnicas ou procedimentos de pesquisa. Nas oficinas de trabalho do Biev, especificamente nas oficinas sobre etnografia sonora, ao ouvir os sons cadastrados e comparar com o preenchimento dos campos, avaliamos que estes termos relacionados a técnicas de pesquisa, mesmo que evocando um determinado resultado produzido pela utilização das técnicas ou procedimentos, não se apresentavam como adequados para descrever a imagem que este resultado expressava. No contexto destas oficinas, nos deparamos com a pergunta de como criar descritores para descrever as formas sonoras dos $i$-sons cadastrados, descritores capazes de qualificar não só o tipo de interação (conversa, diálogo, narrativa oral) anunciando que mais de uma pessoa fala, mas que qualifique também que pessoas são essas (idosos, jovens, alegres, tristes). Trata-se na verdade de uma imersão nos sentidos da imagem sonora para poder capturar sua forma e então construir uma descrição a partir de algumas palavras que contenham esta potência descritiva.

Ao escutarmos os sons acervados, nos deparamos com a complexidade das formas ali presentes: vozes, risadas, conversas, ruídos não identificáveis, sonoridades de gestos, de objetos e utensílios, de ambiências de lugares, de narrativas, entre muitos outros. Mas que vozes são essas, como elas dizem algo? Como soam os objetos e utensílios? Quais as camadas de som presentes em uma ambiência? Todas estas questões têm permeado o trabalho do grupo no sentido de uma precisão cada vez maior da descrição sobre o fenômeno sonoro pesquisado. Ao mesmo tempo, a construção de um bom descritor está diretamente relacionada a uma boa descrição etnográfica da imagem sonora, pois este é o lugar onde é possível apresentar especificidades da situação etnográfica que está para além das sonoridades presentes na imagem. Na descrição etnográfica ficamos sabendo que personagens estão em interação, quais as

\footnotetext{
${ }^{7}$ Referimo-nos aqui as considerações de M. Maffesoli a respeito da teoria da forma em Simmel. "É justamente nesta perspectiva que, adiante, proponho a noção de formismo. Este neologismo pretende fazer justiça à sociologia de G. Simmel, que utiliza o termo formal e não formell: designa o primeiro a forma de um problema; já o segundo refere-se ao aspecto formal.” (MAFFESOLI; 1988: 26).
} 
relações entre eles, seus vínculos, bem como se este som é resultado de uma conversa informal, de uma situação de observação participante, de uma entrevista, etc. Procedendo a uma descrição etnográfica detalhada, podemos estar mais livres para construir um descritor preocupado com a forma.

Isto nos leva a compreensão de que precisamos nos debruçar muito sobre as nuances da imagem sonora, procurando palavras que possam descrevê-las, como nos poemas citados por Michel Chion no primeiro capítulo de Le son (2004). Continuando a discussão e o exercício de escuta, observamos que com o campo descritor, não precisamos apontar todas as sonoridades que aparecem na imagem, mas conseguir delimitar contornos que possam ser compreendidos e capturados por outras pessoas diante do formulário e do acervo. O campo descritor é o que mais nos distancia "carnalmente" da imagem que produzimos em campo. Com a ficha do formulário completamente preenchida, a imagem sonora acervada já não mais nos "pertence" (se é que um dia pertenceu) e também já não é mais a mesma com a qual iniciamos o processo de acervo.

\section{Conclusão}

A construção deste ensaio teve como objetivo explicitar os movimentos interpretativos que estão presentes nos processos de acervamento das imagens sonoras que temos realizado no Banco de Imagens e Efeitos Visuais. Temos claro, neste sentido, que produzir acervos de imagens é um processo bem mais complexo do que "organizar" os dados produzidos em campo. Trata-se de fato de procedimentos analíticos e interpretativos que produzem diferentes resultados no que concerne o campo de conhecimento da Antropologia. Um mais imediato, é a concretude da duração destas imagens sonoras no tempo, tendo em vista seu registro e acervo. Outro são as inúmeras dimensões da produção de pensamento antropológico sobre e a partir das pesquisas pelas imagens que temos desenvolvido no interior do Biev.

Consideramos, na especificidade do acervo de imagens sonoras do Biev, que o pesquisador que produz o cadastro das imagens sonoras que produziu passa por diferentes "giros epistemológicos", mesmo que não os tenha explícitos, devido ao caráter das informações exigidas para se preencher os campos do formulário. Um deles poderíamos ver como "deslocamentos epistemológicos externos", que se dão entre os 
blocos que mencionamos acima, ou seja, sair do conjunto de informações que acessamos de maneira mais direta - ao qual nos referimos aqui ao bloco de informações imediatas - para os campos mais relacionados às reflexões sobre as pesquisas - onde estão presente fonte, fundo de origem, etc - e destes para um movimento mais interpretativo, como é o caso do último bloco mencionado, onde estão os campo descritor, categoria, descrição etnográfica, etc. Um segundo momento destes deslocamentos vividos pelo pesquisador poderíamos ver como "deslocamentos epistemológicos internos" que caracterizam as mudanças de observação da imagem sonora dentro de um mesmo movimento analítico, por exemplo, as nuances entre elaborar uma descrição etnográfica, uma descrição técnica e um descritor.

Esta análise dos movimentos interpretativos do pesquisador diante do acervo estão colocados aqui a titulo de reflexão, no sentido de explicitar as diferentes camadas que constituem a produção de um acervo de imagens. É claro que estes deslocamentos epistemológicos também podem se relacionar com as diferentes formas de cadastro realizada pelos pesquisadores, no sentido de que nem todos vão seguir "a ordem dos campos" para o preenchimento do acervo, podendo optar por uma forma mais "aleatória". O que advogamos importante neste ensaio é justamente o caráter de pesquisa e produção de pensamento antropológico pelas imagens que a construção de acervos de imagens tem nos proporcionado na pesquisa do Banco de Imagens e Efeitos Visuais.

\section{Referências}

BACHELARD, Gaston. A Dialética da Duração. São Paulo, Editora Ática, 1988.

BACHELARD, Gaston. A Poética do Devaneio. São Paulo, Martins Fontes, 1996.

BACHELARD, Gaston. A Poética do Espaço. São Paulo, Editora Ática, 2000.

CHION, Michel. Le son.Paris, Armand Colin, 2004.

DURAND, Gilbert. A Imaginação Simbólica, São Paulo, Cultrix: Editora da Universidade de São Paulo, 1988.

DURAND, Gilbert. As Estruturas Antropológicas do Imaginário. São Paulo, Martins Fontes, 2001.

ECKERT, Cornelia \& ROCHA, Ana Luiza C. da $O$ tempo e a cidade. Coleção Academia II. Porto Alegre, Ed. da UFRGS, 2005, e o artigo "Etnografia de rua, estudos de antropologia urbana". In: RUA - Revista do Núcleo de Desenvolvimento da Criatividades da UNICAMP - NUDECRI. Campinas, SP, n. 9, março 2003.

GEERTZ, Clifford. Obras e Vidas: o antropólogo como autor. Rio de Janeiro: Editora UFRJ, 2002.

MAFFESOLI, Michel. O Tempo das Tribos. $O$ declínio do individualismo na sociedade das massas. Forense Universitária, Rio de Janeiro, 1987. 
MAFFESOLI, Michel. O Conhecimento Comum. Compêndio de Sociologia Compreensiva. Editora Brasiliense, São Paulo, 1988.

RICOEUR, Paul. Tempo e Narrativa. Volume I São Paulo, Papirus, 1994.

ROCHA, Ana Luiza Carvalho da. VEDANA, Viviane. A representação imaginal, os dados sensiveis e os jogos da memória: os desafios do campo de uma etnografia sonora. In: Anais do VII Congresso de Antropologia do Mercosul (VII-RAM), Porto Alegre, 2007, CD-ROOM.

VEDANA, Viviane. Sonoridades da Duração: práticas cotidianas de mercado no mundo urbano contemporâneo. Uma introdução à construção de coleções etnográficas a partir dos dados imagéticos de campo. In: Anais do VII Congresso de Antropologia do Mercosul (VII-RAM), Porto Alegre, 2007, CD-ROOM. 